\title{
Development of electron diffraction techniques for ab initio crystal structure determination and phase analysis - from zeolites to proteins
}

\author{
Xiaodong Zou
}

Department of Materials \& Environmental Chemistry, Stockholm University, Sweden, xzou@mmk.su.se

Electron diffraction (ED) has unique advantages in studying nano- and micrometer-sized crystals[1]. Although ab initio structure solution using ED was already demonstrated in the 90s [2], it was not widely used. During the past decade, several groups have developed new methods to collect 3D ED data, with various technique solutions on different microscopes [3-8]. These have opened new possibilities for structural studies of nano- and micorcrystals.

My group developed rotation electron diffraction (RED) and corresponding software for data collection and processing [4,5]. Today, a complete 3D ED dataset can be obtained in less than a minute. The data processing, structure solution and refinement are performed using standard X-ray crystallography software. My group has determined more than 100 structures using 3D ED data including inorganic and organic compounds and protein microcrystals (Fig. 1). We have shown that the method is robust, and the structure models can reach better than $0.10 \AA$ in accuracy.

To automate data collection, we developed serial electron diffraction (SerialED) by taking ED patterns (snapshots) of individual particles [9]. ED patterns from more than $>3500$ particles can be collected automatically in less than one hour on a standard TEM. We also combined data collection by SerialED with RED and developed SerialRED to perform fully automated data collection and data analysis for 3D electron diffraction [10]. This provides new possibilities for studying very beam sensitive crystals. The large number of particles makes it possible for phase analysis, and for detection of minor phases in the sample.

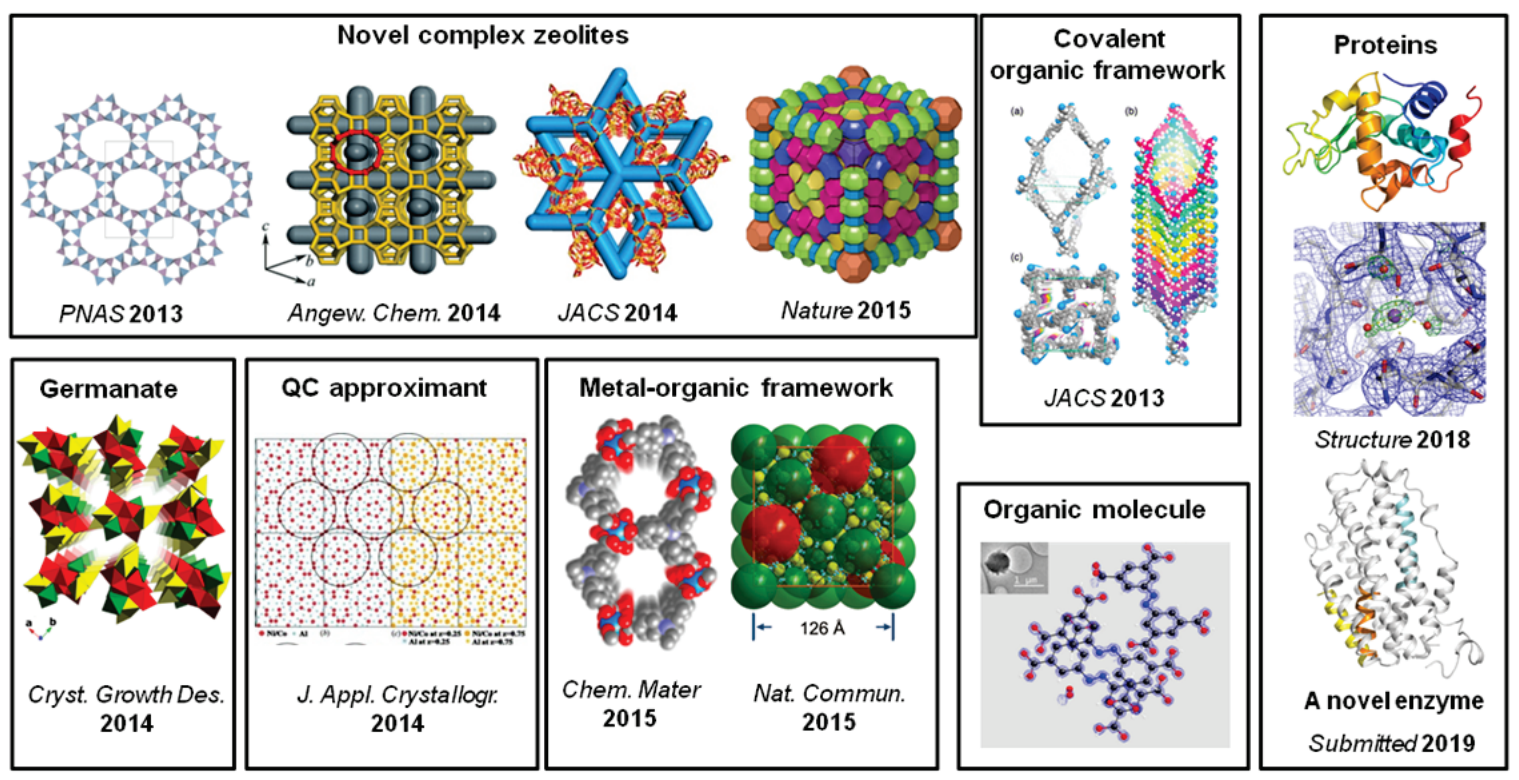

Fig. 1 Selected examples from $>100$ structures solved using RED by my group.

[1] X. Zou, S. Hovmöller, P. Oleynikov, Electron Crystallography, Oxford University Press, 2011

[2] T.E. Weirich, X. Zou, R. Ramlau, A. Simon, G. L. Cascarano, et al., Acta Cryst. 2000, A56, 29.

[3] U. Kolb, T. Gorelik, C. Kübel, M.T. Otten, D. Hubert, Ultramicroscopy, 2007, 107, 507.

[4] D. Zhang, S. Hovmöller, P. Oleynikov, X. Zou, Z. Kristallogr. 2010, 225, 94.

[5] W. Wan, J.L. Sun, J. Su, S. Hovmoller, X Zou, J. Appl. Cryst. 2013, 46, 1863.

[6] I. Nederlof, E. van Genderen, Y. Li, J.P. Abrahams. Acta Crystallogr. 2013, D69, 1223.

[7] B.L. Nannenga, D. Shi, A.G.W.Leslie, T. Gonen, Nat. Methods 2013, 11, 927-930.

[8] M. Gemmi, M.G.I. La Placa, A.S. Galanis, E.F. Rauch, S. Nicolopoulos, J. Appl. Cryst. 2015, 48, 718.

[9] Y. Wang, T. Yang, H. Xu, X. Zou, W. Wan, J. Appl. Cryst. 2018, 51, 1094

[10] S. Smeets, X. Zou, W. Wan, J. Appl. Cryst. 2018, 51, 1262.

[11] B. Wang, X. Zou, S. Smeets, 2019, submitted. 